\title{
A study on performance characteristic: The effect of different parameter of renewable energy application
}

\author{
Nadia Tajudin ${ }^{1}$, M. H. Amlus ${ }^{1, *}$, Amlus Ibrahim ${ }^{2}$, Ahmad Zaidi Abdullah $^{1}$ and Ummi Naeimah Saraeh ${ }^{1}$ \\ ${ }^{1}$ Universiti Malaysia Perlis, Malaysia \\ ${ }^{2}$ Universiti Utara Malaysia, Malaysia
}

\begin{abstract}
Malaysia government still identify the best system in giving people solution on renewable energy. This study will focus on the performance of PV module. The characteristic of PV module still can be argued especially in absorbing the direct effect of sun light energy. The previous authors were not having a specific solution on the problem of the PV module implication after received the direct effect of sun light. This study will suggesting on the innovation of the process and system of PV module and restructuring the characteristic and provides information. The tools of quality PDCA and (OEE) will be used to identify the best solution using the different type of cooling system. From this information, the stake holder can decrease the cost of using this type of technology.
\end{abstract}

\section{Introduction}

As the world is facing the problem of energy deficit global warming and detoriation of environment and energy sources, there is need for an alternative energy resource for power generation other than use of fossil fuels, water and wind. Solar energy is the one of the comparable candidates for alternative energy source. (Arnav, 2016). It is important in order to address transformation of climate because the global warming and reduction ozone layer which are the example environmental phenomenon that cause by the emission from combustion of massive fuel are slowly making problem to each living thing on the earth.

According to Hasanuzzaman (2015), the volume of $\mathrm{CO} 2$ and other harmful greenhouse gases is increase steeply in the environment and worsening the climate state further. So that, the renewable energy applications are the most prospective solution to this vulnerable situation. PV electricity generation is the among the renewable energy technologies is one of the potential option to encounter the future the predicament. Being a clean source of energy, the PV system has great potential, especially in the tropical area. Besides, PV technology is also one of the best solution to reduce the environmental phenomenon. PV not only the renewable energy but also sustainable energy where convert the solar radiation into the electricity that can use to supply the domestic power.

PV module is a device which directly changes the sunlight energy into the electrical energy. The power from the sun intercepted from the earth by the earth is approximately $1.8 \times 1011 \mathrm{MW}$ which is bigger than the present consumption rate on the earth off all commercial energy sources. The performance of PV module effected by it temperature based on the power $(\mathrm{W})$, voltage $(\mathrm{V})$ and current (A). The higher the temperature of PV module lead to the lower electricity produced. However, the main problem related to the PV is their efficiency. The $15 \%$ is the ideal range for PV module where the remaining energy is changed to the heat. The heat will increase the operating temperature of PV module, so that the electrical production 3

will affect. Besides, it will damage the PV module where reduce the life span of PV module and also reduce the conversion efficiency. The PV efficiency can be increase by lowering the temperature of PV. (Arnav, 2016).

\section{Method}

This study uses the design in Performance of PV module. The propose of using the study research is because to identify the effect of liquid cooling system toward the Performance of PV module and to collect detailed factual information that describes existing Phenomena. The figure below shows the flow of research design. 


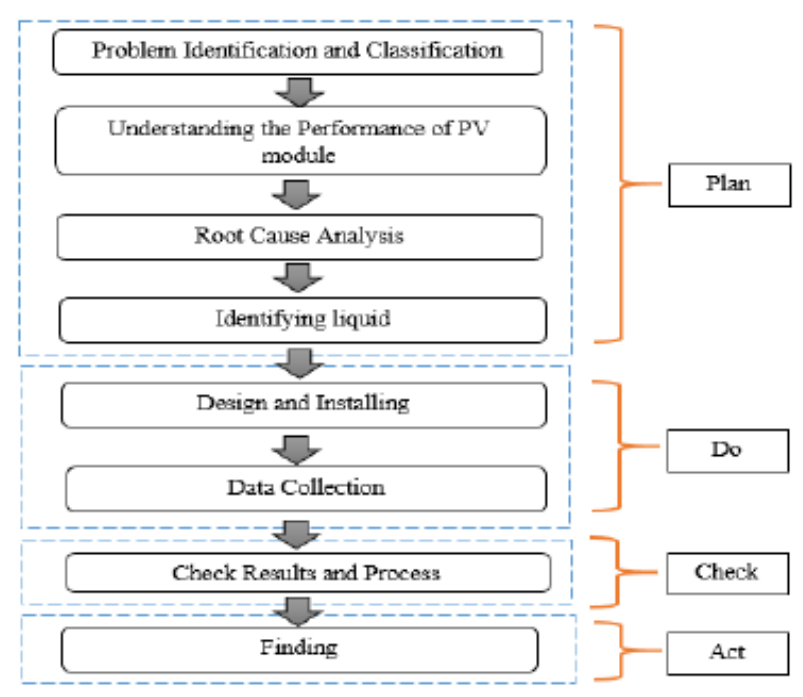

Figure 1: Research Design Flow

The Overall Equipment Effectiveness is a main performance indicator that can be applied for benchmarking, evaluating and increasing production processes by measuring inefficiencies and classifying them in dissimilar categories. In addition, in the manufacturing process, OEE is the total use of time, materials and facilities.

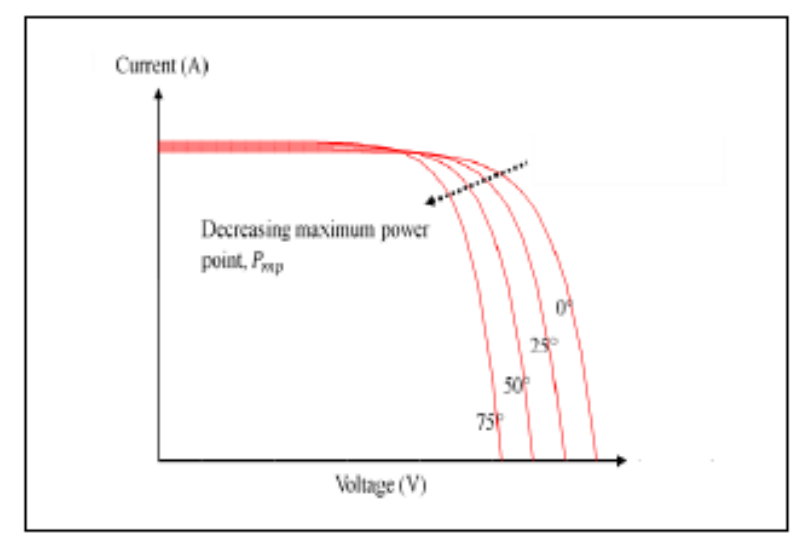

Figure 2: Voltage (V) versus Current (A)

The formula of OEE;

Performance $=$ Ideal Cycle Time $/$ (Time operation/ Pieces Total)

OEE takings into account contributing factors and is calculated as

OEE=Avaibility x Performance $x$ Quality

\section{Result Analysis}

\begin{tabular}{|c|c|c|c|c|c|c|}
\hline Day & Liquid & Time & $\begin{array}{c}\text { Temperature } \\
\left({ }^{\circ} \mathrm{C}\right)\end{array}$ & $\begin{array}{l}\text { Voltage } \\
\text { (V) }\end{array}$ & $\begin{array}{l}\text { Current } \\
\text { (I) }\end{array}$ & $\begin{array}{l}\text { Power } \\
\text { (W) }\end{array}$ \\
\hline \multirow[t]{30}{*}{1} & Coolant & 8.00 & 23.4 & 18.14 & 0.13 & 2.36 \\
\hline & & 9.00 & 25.3 & 19.13 & 0.14 & 2.68 \\
\hline & & 10.00 & 27.3 & 19.36 & 0.14 & 2.71 \\
\hline & & 11.00 & 28.3 & 19.87 & 0.16 & 3.39 \\
\hline & & 12.00 & 41.6 & 19.95 & 0.17 & 3.39 \\
\hline & & 1.00 & 45.3 & 19.75 & 0.19 & 3.75 \\
\hline & & 2.00 & 56.3 & 19.57 & 0.23 & 4.50 \\
\hline & & 3.00 & 37.2 & 19.61 & 0.25 & 4.90 \\
\hline & & 4.00 & 56.5 & 19.41 & 0.23 & 4.46 \\
\hline & & 5.00 & 33.2 & 19.26 & 0.20 & 3.85 \\
\hline & Water & 8.00 & 24.3 & 17.93 & 0.1 & 1.79 \\
\hline & & 9.00 & 26.2 & 19.1 & 0.11 & 2.10 \\
\hline & & 10.00 & 27.5 & 19.32 & 0.11 & 2.13 \\
\hline & & 11.00 & 31.0 & 19.65 & 0.13 & 2.74 \\
\hline & & 12.00 & 42.9 & 19.81 & 0.16 & 3.37 \\
\hline & & 1.00 & 45.5 & 19.54 & 0.17 & 3.29 \\
\hline & & 2.00 & 56.5 & 19.42 & 0.18 & 3.50 \\
\hline & & 3.00 & 39.6 & 19.48 & 0.23 & 4.48 \\
\hline & & 4.00 & 57.4 & 19.35 & 0.20 & 3.87 \\
\hline & & 5.00 & 33.6 & 19.21 & 0.15 & 2.86 \\
\hline & Without & 8.00 & 25.5 & 17.48 & 0.09 & 1.57 \\
\hline & Cooling & 9.00 & 27.5 & 18.79 & 0.09 & 1.69 \\
\hline & System & 10.00 & 27.6 & 18.97 & 0.10 & 1.90 \\
\hline & & 11.00 & 36.0 & 19.38 & 0.11 & 2.13 \\
\hline & & 12.00 & 46.4 & 19.65 & 0.12 & 2.36 \\
\hline & & 1.00 & 49.0 & 19.33 & 0.13 & 2.51 \\
\hline & & 2.00 & 58.0 & 19.25 & 0.16 & 3.08 \\
\hline & & 3.00 & 40.3 & 19.31 & 0.15 & 2.90 \\
\hline & & 4.00 & 58.9 & 19.23 & 0.15 & 2.88 \\
\hline & & 5.00 & 34.0 & 19.09 & 0.12 & 2.29 \\
\hline
\end{tabular}

Figure 3: Reading for day 1

The data of Temperature $\left({ }^{\circ} \mathrm{C}\right)$, Voltage (V), Current (A) and Power (W) for the PV module without and with liquid cooling system (water and coolant) for day 1 was collect from 8.00 am to $5.00 \mathrm{pm}$.

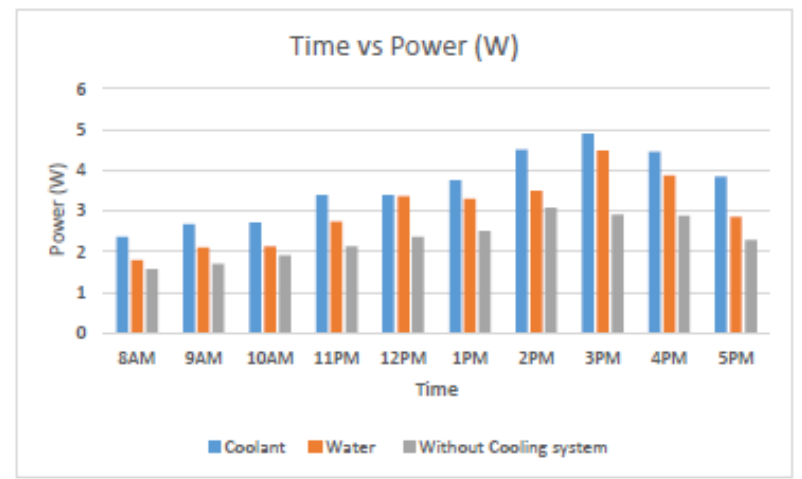

Figure 4: Graph Time vs Power (W)

From the figure 4, it can note that the temperature reading of PV module with no cooling system has biggest value. It is followed by the PV with water and PV with coolant based on measurement in table. The performance of voltage (V), current (A) and power (W) of PV with no cooling system has affected because of higher temperature. The higher the temperature lead to lowest of voltage (V), and power (W) of PV module. Therefore, the efficiency of PV module will decrease.

Besides, it is shown that comparing to the PV module with water, the PV module with coolant has lowest temperature. As the temperature is lowest, the performance of voltage $(\mathrm{V})$, current (A) and power (W) of PV module is highest. Hence, it leading to the improvement of the PV module efficiency. 


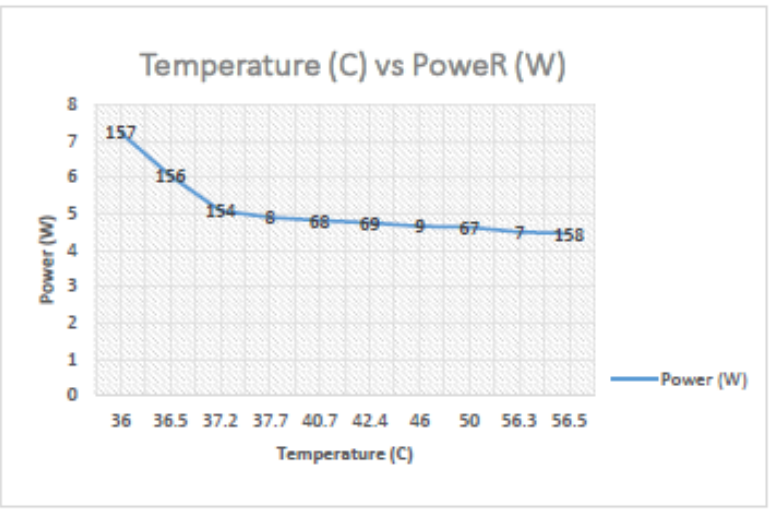

The graph is presented of Temperature $\left({ }^{\circ} \mathrm{C}\right)$ versus Power (W) of coolant as cooling system. It can see that, the increasing reading value of temperature will lead to decreasing reading value of Power (W). Therefore, it can conclude that, the higher the temperature, the lower the output of PV model.

\section{Conclusion}

By referring to the findings, some of the strategies can be suggested. From the results, it can be determine that the performance of PV module effected by it temperature according to the power (W), voltage (V) and current (A). The higher the temperature of PV module lead to the lower electricity produced. Moreover, the lifespan of PV module will reduce due to the higher temperature. The PV cooling system's designing and installing is significant to solve the problem of PV module. The PV module's wall is cooled by the liquid flowing resulting the temperature of PV module remains constant. Therefore, higher electricity will produce.

As discussed previously, the main aspect when choosing liquid cooling for cooling systems is the compatibility of heat transfer fluid. Compatibility of heat transfer fluid is significant to make sure a long-term reliability system. Several of the required heat transfer fluids may consist of huge thermal conductivity and certain heat, low viscous, low frozen, great flash point, loww corrosion, low toxic, and thermal stability. Therefore, water is choosed based on high heat evaporation, less viscosity and the most important is water very costly.

Through choosing a compatible heat transfer fluid and wet material, it will decrease the possibility of corrosion and increase thermal performance. As example, copper is proper for water and glycol/water and aluminum solutions that are compatible with glycol / water solution and oils.

However, the using of deionized water or corrosive liquids, recommended that the stainless steel which has more resistant to corrosion compare to other metals. The systems of cooling are mostly compatible with water or glycol / water solutions but require special pipes for compatibility with deionized water or dielectric liquids such as polyalphaolefin (PAO).

From the study, by using the different type of cooling sytem will provide the different output. The stake holder can have some choices in selecting the different material according to their cost and output.

From this study, the best cooling system is by using coolant. It will give a significant Power and can establish the current, temperature and voltage.
The second option, the best decision in controlling the system of PV module is by using water. From this study, there are not much different in term of the output - Power by using this type of cooling solution. So the stake holder or the decision maker of company can suggest this type of cooling solution.

And the PV module will provide a lowest Power if using the system without cooling system. The stake holder need to aware the implication of using PV module without using any cooling system.

\section{References}

Bhaskar B Gardas1, 2, M V Tendolkar1 (2012, ) Design of Cooling System for Photovoltaic Panel for Increasing Its Electrical Efficiency pp 144-149

H.G. Teo, P.S. Lee, M.N.A. Hawlader,"An Active Cooling System for PV Modules," Applied Energy, Vol.90, pp. 309-315, 2012.

Jiang Wu, Zhou Shi, Shuai Zheng, Lalu Zhao, Qiaobo Feng, Hancheng Luo Sheng Yang, Yujing Wang, "Research on heat transfer characteristics of solar cells and heat exchanger combined system and its optimization," Energy Procedia 2012; 14: 393- 398.

M. Lesshammar, "Evaluation and improvement of manufacturing performance measurement systems - the role of OEE", International Journal of Operations and Production Management, vol. 19 , no. 1, (1999), 55-78.

Priyanka Singh, S. N. Singh, M. Lal, M. Husain, "Temperature Dependence of I-V Characteristics and Performance Parameters of Silicon Solar Cell," Solar Energy Materials \& Solar Cells, Vol.92, pp.1611-1616,2008.

Y. M. I. Z. Farhana, R.M.N Azimmi, A.R.N.Razliana, N. Gomesh, "Symposium on Computers and Informative," Experimental Investigation of Photovoltaic Modules Cooling System, pp. 165169.

Y. M. Irwan, W.Z. Leow, M. Irwanto, Fareq.M, A.R. Amelia, N.Gomesh, I.Safwati, "Indoor Test Performance of PV Panel through Water Cooling Method," Energy Procedia 2015; 79 : 604611. 